\title{
Effect of a Nursing In-Service Education Program on Nurses' Knowledge and Attitudes towards Pain Management in a Governmental Hospital in the United Arab Emirates: Experimental Random Assignment Study
}

\author{
Nezar Ahmed Salim ${ }^{a}$ Rennie Joshua ${ }^{a}$ Noora Abdulmajid AbuBaker ${ }^{a}$ \\ Fouad Chehab ${ }^{\mathrm{b}}$ Ambily Jose ${ }^{\mathrm{a}}$ \\ ${ }^{a}$ In-Service Education Department, Dubai Hospital, Dubai Health Authority, Dubai, United Arab Emirates; ${ }^{\text {b Nursing }}$ \\ Department, Dubai Hospital, Dubai Health Authority, Dubai, United Arab Emirates
}

\section{Keywords}

Pain management program - In-service education - Attitude . Knowledge $\cdot$ United Arab Emirates

\begin{abstract}
Background: Pain is the most common symptom, which is often experienced in acute illnesses and is one of the symptoms that patients feel apprehensive about. Undertaking pain management aims to prevent negative physiological and psychological outcomes. Inadequate knowledge about pain and its characteristics is a common barrier to effective pain management. Evidence shows that if nurses have adequate knowledge and a positive attitude towards pain, it may lead to more effective pain management. Objectives: The main goal of this study is to assess the effect of nursing in-service education program on nurses' knowledge and attitudes concerning pain management in one of the governmental hospitals in Dubai, United Arab Emirates. Methodology: This study has a quantitative-experimental, random assignment design with a pre-test/post-test approach used in one of the governmental hospitals in Dubai, United Arab Emirates. The study was carried out between February and April 2019. The sample of this study consisted of 200 partici-
\end{abstract}

\begin{tabular}{ll}
\hline KARGER & $\begin{array}{l}\text { (c) } 2019 \text { The Author(s) } \\
\text { Published by S. Karger AG, Basel }\end{array}$ \\
E-Mail karger@karger.com & $\begin{array}{l}\text { This article is licensed under the Creative Commons Attribution- } \\
\text { NonCommercial-NoDerivatives 4.0 International License (CC BY- } \\
\text { NC-ND) (http://www.karger.com/Services/OpenAccessLicense). } \\
\text { Usage and distribution for commercial purposes as well as any dis- } \\
\text { tribution of modified material requires written permission. }\end{array}$
\end{tabular}

pants selected randomly from the units in the hospital by simple randomization through the software SPSS version 20 . The experimental group received the pain management program (PMP) over $5 \mathrm{~h}$. The participants were exposed to a pre-test and after receiving the PMP, they were administered the post-test, while in the control group the pre-test and the post-test were carried out without intervention. Result: The paired $t$ test was used to find the mean difference between pre- and post-intervention. The findings of the experimental group revealed that the mean score on the Knowledge and Attitudes Survey Regarding Pain (KASRP) increased after the intervention from 61.36 (SD 11.60) to 69.94 (SD 7.74) with a mean difference of $8.58(t(99)=-5.97, p<0.05)$, while in the control group the mean score on the KASRP slightly decreased following the test (mean \pm SD, $60.99 \pm 11.53 \%$ ) compared to the pre-test (mean $\pm S D, 61.00 \pm 11.60 \%$ ) with a mean difference of $0.01(t(99)=1.41, p>0.05)$. Conclusion and Recommendation: In-service education PMP proved to be effective. Pain knowledge and attitudes were improved after the educational session. Nurses in the experimental group scored higher in the post-test but still did not reach the passing score of $75 \%$. Moreover, the knowledge scores increased significantly after implementing the PMP. As concluded from the current study, well-structured in-service ed-
Nezar Ahmed Salim

Dubai Health Authority, Education Department

Dubai Hospital, Al-Baraha Street

Dubai 00971 (United Arab Emirates)

E-Mail Nezar_dubai30@yahoo.com 
ucation sessions are able to improve knowledge and show an impact on attitude changes. Since the PMP proved to be effective, it is recommended to be implemented in daily nursing practice.

(C) 2019 The Author(s)

Published by S. Karger AG, Basel

\section{Introduction}

Pain is the most common symptom, which is often experienced in acute illnesses and is one of the symptoms that patients feel apprehensive about [1]. Undertaking pain management aims to prevent negative physiological and psychological outcomes [2]. Since pain assessment is considered the responsibility of nurses, nurses are required to utilize the appropriate assessment measures and intervene accordingly [3]. Untreated pain may cause multisystem complications and the progression of chronic unrelenting pain leading to impaired body functioning and disturbed quality of life and well-being [4]. Many patients experience significant pain during hospitalization. For example, more than $30 \%$ of ICU patients suffer from pain at rest, and more than $50 \%$ complain about pain during routine care, such as endotracheal suctioning, wound care and changing [5].

A previous study was conducted by the same authors to assess the situation in the United Arab Emirates in two governmental hospitals. The result revealed that the staff nurses in both hospitals have poor knowledge and a nonstandard attitude. The mean score on the Knowledge and Attitudes Survey Regarding Pain (KASRP) was 45\%, significantly below the passing score of $80 \%$ [6].

A handful of international studies have examined nurse knowledge of pain management showing that nurses from Turkey (35\%) [7], Italy (55\%) [8], Iran (66.6\%) [9], Saudi Arabia (42\%) [10], Canada (41\%) [11], and the
United States (72\%) [12] have inadequate knowledge and attitudes regarding pain as measured by the Nurses Knowledge and Attitudes Survey Regarding Pain (NKARSP) (Table 1).

Relief of pain is an important nursing goal epitomized in the profession's philosophy [13]. Nurses are in charge of regular assessment of pain, medication administration and monitoring of the patients' responses [14].

Inadequate knowledge about pain and its characteristics is a common barrier to effective pain management [15]. Ineffective pain management skills by nurses and nurses' disinclination to embrace all dimensions regarding pain is problematic [16]. For instance, nurses were observed to have insufficient knowledge about opioid analgesic drugs [17]. They may develop different perspectives towards pain; thereby, they may subjectively judge the patients' pain level based on personal opinions or rituals [17].

Although pain control for hospitalized patients is considered a central concern for all health care providers, crucial barriers are presented by nurses' lack of knowledge, insufficient assessment skills, negative attitudes and reluctance to act as the patients' advocate [18] and misconceptions [14]. Inadequate pain management reflects deficient knowledge on the nurses' part. Adequate pain management knowledge aids nurses to support their practices of pain assessment, medication administration and monitoring [19]. The beliefs and attitudes of nurses may influence patient care [20]. Evidence shows that if nurses have adequate knowledge and a positive attitude towards pain, it may lead to more effective pain management [21]. Nurses who believe in the significance of patient pain relief implement more pain management activities [22], and nurses with a positive attitude have the aim and motivation to provide care for a patient with pain [20]. Previous studies have shown that in-service pain ed-

Table 1. Summary of international scores of the Pain Knowledge and Attitudes Survey

\begin{tabular}{|c|c|c|c|c|}
\hline Authors & Country & Year & Sample size & $\begin{array}{l}\text { Mean } \\
\text { score }\end{array}$ \\
\hline Brunier et al. [11] & Canada & 1995 & 514 & $41 \%$ \\
\hline Bernardi et al. [8] & Italy & 2007 & 287 & $55 \%$ \\
\hline Yildirim et al. [7] & Turkey & 2008 & 608 & $35 \%$ \\
\hline Shahriary et al. [9] & Iran & 2015 & 58 & $66.6 \%$ \\
\hline Eid et al. [10] & Saudi Arabia & 2014 & 593 & $42 \%$ \\
\hline Brant et al. [12] & United States & 2017 & $217 \mathrm{RNs}$ & $72 \%$ \\
\hline Al-Atiyyat et al. [6] & United Arab Emirates & 2019 & 115 & $45 \%$ \\
\hline
\end{tabular}

RNs, registered nurses.

Effect of In-Service Education on Pain Management
Dubai Med J 2019;2:146-152

DOI: $10.1159 / 000503560$ 
ucation programs improved nurses' knowledge and attitudes toward pain management [23]. Nevertheless, levels of education and the culture of nursing practice may vary within and between countries.

There are no studies in the United Arab Emirates discussing the effect of nursing in-service education pain management program (PMP) on the nurses' knowledge and attitudes. Thus, this is the first study to highlight this issue. The main goal of this study is to assess the effect of the nursing in-service education program on the nurses' knowledge and attitudes concerning pain management in one of the governmental hospitals in Dubai, United Arab Emirates.

\section{Methodology}

\section{Setting, Design, Sample}

This study is a quantitative, experimental, simple random sampling design with a pre-test/post-test approach used in one of the governmental hospitals in Dubai, United Arab Emirates. The study was carried out between February and April 2019. The sample size was calculated based on group comparisons using a twosample $t$ test. Based on an effect size of $0.25,95 \%$ power, and significance of $p<0.05$, a total sample of 132 was determined. The participants who were selected for this study were nurses with more than 1 year of experience in dealing with or directly caring for patients, and who can fully understand and speak the English language.

\section{Study Procedure}

An in-service education program with theoretical sessions was conducted by the in-service education members in the classroom of the hospital. The principal investigator had developed a 5-h PMP. The pain education included: (1) introduction to pain man- agement, covering pain definitions, pathophysiology, and the current trends in pain management; (2) pain assessment; and (3) pharmacological and nonpharmacological pain interventions. The participants were divided into two groups: an experimental and a control group. Sample distribution was done by using simple random sampling through SPSS. The experimental group received the PMP, which lasted $5 \mathrm{~h}$, over two sessions to ensure the hospital unit workflow as did the control group. The participants of the experimental group were exposed to a pre-test and after having received the PMP, they were administered the post-test, while the control group received the pre-test and post-test without intervention (Fig. 1). The PMP was submitted to the accreditation committee for review of the content and for grant of the CPD (continuing professional development) hours. Several educational strategies were followed, such as educational materials, videos and casebased discussion. Teaching materials included standardized pain assessment materials and books. Approval has been obtained under the accreditation No. 0095\19.

Data collection was carried out using a structured, self-administered instrument (KASRP) consisting of 39 questions, 22 of which being true/false questions, 15 multiple-choice questions, and 2 scenarios. The tool was identified as discriminating between levels of expertise. It was developed by Betty Ferrell in 1987. She has been contacted by email to get permission to use and translate the tool. The tool is available on the website: http://prc.coh.org [25]. The validity and reliability of the tool were checked by the author.

\section{Data Analysis}

Data were checked for completeness and accuracy prior to data coding and entry. Data analysis has been conducted by using SPSS 20 software. The data have been tested at a 5\% level of significance and $p<0.05$ was considered significant. Descriptive statistics were used to find the frequency, percentage, and mean and standard deviation. In addition, a two-sample $t$ test was carried out to compare the knowledge score between the two groups (pre-score and postscore), and the sample size was calculated based on comparing the post-score between the experimental and the control groups.

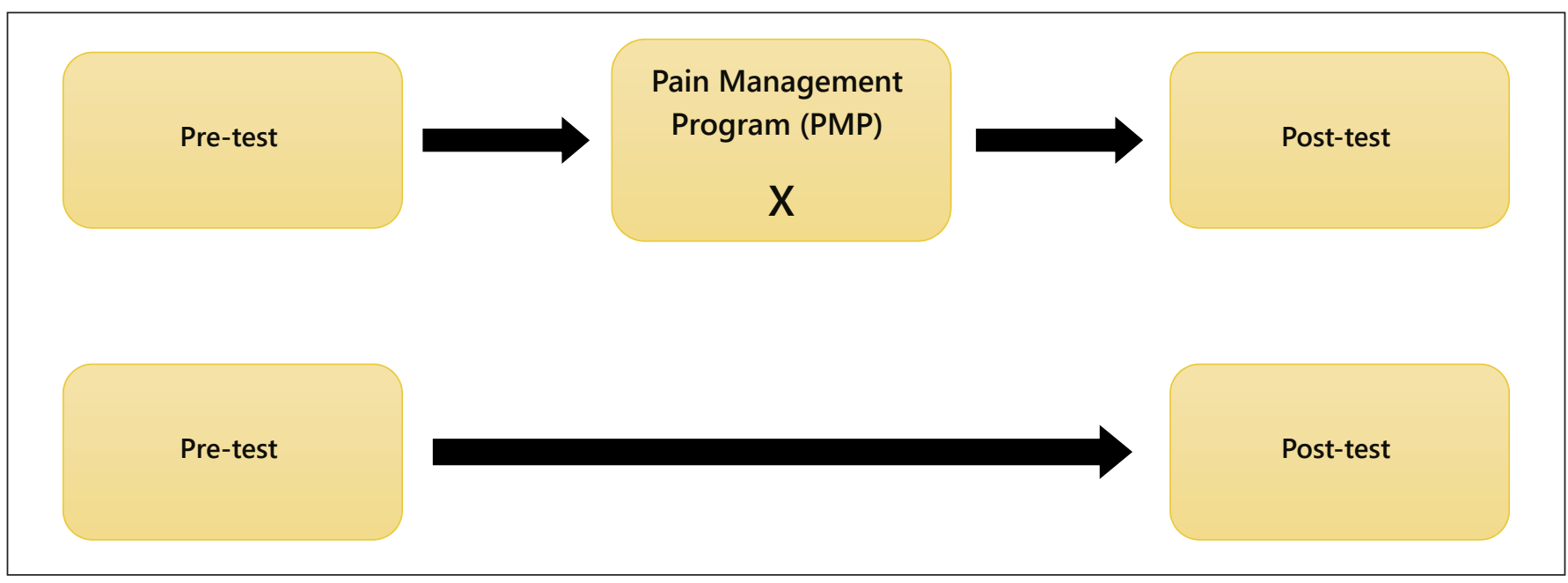

Fig. 1. Study design and procedure. 
Table 2. Participants' demographical data

\begin{tabular}{lc}
\hline Gender & \\
Male & $20(10 \%)$ \\
Female & $180(90 \%)$ \\
Nationality & $15(7.5 \%)$ \\
Arab & $85(42.5 \%)$ \\
Filipino & $92(46 \%)$ \\
Indian & $8(4 \%)$ \\
Other & \\
Level of education & $14(7 \%)$ \\
Diploma & $170(85 \%)$ \\
BSN & $16(8 \%)$ \\
Master & $64(32 \%)$ \\
Marital status & $134(67 \%)$ \\
Single & $2(1 \%)$ \\
Married & \\
Other & $50(33 \%)$ \\
Previous pain course & $150(67 \%)$ \\
Yes & \\
No & $35.43 \pm 8.134$ \\
Continuous variables (mean \pm SD) & $11.88 \pm 6.289$ \\
Age, years & \\
Experience, years &
\end{tabular}

\section{Ethical Consideration}

The ethical consideration was taken up to standard. The study was reviewed by the scientific research committee. Institutional Review Board approval (Ref. No. DSREC-06/2018_07) had been obtained prior to data collection. In order to start data collection, the questionnaire and consent form were given to the participants who met the inclusion criteria. An information sheet was attached to the questionnaire explaining the purpose of the study. The nurses assured that confidentiality and privacy of the answers are granted. No names, phone numbers and identification are required.

\section{Results}

\section{Demographical Data}

The sample consisted of 200 participants; $10 \%$ of the sample were male and $90 \%$ female. Among the participants, $67 \%$ were married, $32 \%$ single, and $1 \%$ others. In terms of the nationality, $46 \%$ of the respondents were Indians, $42.5 \%$ Filipino, $7.5 \%$ Arabs, and $4 \%$ others.

The study reveals that the majority of the participants have a bachelor's degree (85\%), $8 \%$ have a master's degree, and $7 \%$ are diploma holders. Regarding education related to pain management, $62.5 \%$ had received training, while $37.5 \%$ had never attended any sessions related to pain management. The mean age $( \pm \mathrm{SD})$ of the participants was $35.43 \pm 8.134$ years, while the mean experience was $11.88 \pm 6.289$ years (Table 2).

Effect of In-Service Education on Pain Management

\section{Statistical Analysis}

Regarding between-group comparisons, no significant difference existed between the pre-test scores for the experimental and the control groups $(p=0.30)$. However, a significant difference existed in the post-test scores $(p<$ 0.01 ), with the experimental group scoring significantly higher than the control group. Both the experimental and control groups were analyzed separately. When the experimental group was analyzed, all respondents increased their knowledge on the KASRP at the post-test. On average, participants answered $61.36 \%$ of the survey items correctly before the intervention and $69.94 \%$ after the intervention. The findings revealed that the mean score on the KASRP increased after intervention from $61.36 \pm$ 11.60 (mean \pm SD) to $69.94 \pm 7.74$, with a mean difference of $8.58(t(99)=-5.97, p<0.05)$.

In terms of the control group, all respondents maintained the same knowledge and even less on the KASRP at the post-test. The findings revealed that the mean score on the KASRP slightly decreased at the post-test (mean \pm $\mathrm{SD}, 60.99 \pm 11.53 \%)$ compared to the pre-test $(61.00 \pm$ $11.60 \%)$ with a mean difference of $0.01(F(99)=1.41, p>$ 0.05 ; Table 3 ).

\section{Discussion}

The findings of the current study showed a significant improvement in the mean scores of nurses regarding pain management following participation in the PMP. It provides important information about the effect of an education program on nurses' knowledge and attitudes regarding pain management. Allard et al. [26] and Bennett et al. [27] found that one session of educational exposure was not inferior to multiple episodes of education.

It is worth noting that the baseline knowledge in the United Arab Emirates (61.36\%) was better compared to Canada (41\%) [11], Italy (55\%) [8], and Turkey (35\%) [7]. On the other hand, the situation was better in the United States (72 \%) [12] and in Iran (66.6\%) [9]. Comparing the situation in the gulf area, the baseline knowledge was better compared to a study conducted in Saudi Arabia (42\%) [10].

A handful of studies conducted earlier confirmed the findings of the current study and that inadequate knowledge and a nonstandard attitude toward pain could be enhanced by an in-service education PMP $[19,28]$.

Post-test scores reported here are more similar to those detected in a nationwide survey, which concludes that nurses who received the PMP significantly increased both in mean score and pain assessment practice [29]. When 
Table 3. Proportion of correct answers and mean pre-test and post-test KASRP scores by using the paired $t$ test

\begin{tabular}{|c|c|c|c|c|c|c|}
\hline & \multicolumn{3}{|c|}{ Experimental group } & \multicolumn{3}{|c|}{ Control group } \\
\hline & pre-test & post-test & & pre-test & post-test & \\
\hline Mean \pm SD & $61.36 \pm 11.60$ & $69.94 \pm 7.74$ & & $61.00 \pm 11.60$ & $60.99 \pm 11.53$ & \\
\hline$N$ & 100 & 100 & & 100 & 100 & \\
\hline $\begin{array}{l}\text { Standard error of the } \\
\text { mean }\end{array}$ & 1.16 & 0.77 & & 1.16 & 1.15 & \\
\hline Mean difference & & & -8.58 & & & -0.01 \\
\hline$t$ & & & 5.97 & & & 1.41 \\
\hline df & & & 99 & & & 99 \\
\hline Significance ( $p$ value) & & & $<0.05$ & & & $>0.05$ \\
\hline
\end{tabular}

compared to the results reported by Ferrell et al. [30] using the same instrument (NKAS), this study found average pre-test scores (61.36 vs. $58.4 \%)$ and the improvement of post-test score was significant $(p<0.05)$ in both groups. The same conclusion was noticed in a study conducted by Machira et al. [31] that nurses' knowledge and attitudes towards pain, besides their ability to assess pain, were shifted from negative to positive competency after receiving pain education. A quasi-experimental study with control groups confirmed that after the educational intervention, the registered nurses' knowledge and attitudes regarding cancer pain management could be effectively changed [32]. Similarly, evidence was found that nurses' knowledge and attitudes regarding pain management have improved after introducing a PMP [33].

When comparing the scores in the control group, there was no significant difference. Hence, the result of the pre-test was $61.00 \pm 11.60 \%$ (mean $\pm \mathrm{SD}$ ) compared to $60.99 \pm 11.53 \%$ for the post-test $(p>0.05)$. Sharif et al. [34] observed that there is no significant improvement in staff knowledge 2 weeks after intervention. Tse and Ho [35] found, upon completion of the PMP, that the scores for pharmacological knowledge remained low, while Machira et al. [31] report a significant difference in the NKAS pre-test and post-test score among the participants in the experimental group. No significant difference was noticed between post-test and follow-up among the participants in the control group.

An improper PMP in the staff nurses' educational curriculum or even their hospital setting can attribute to inadequate knowledge and a nonstandard attitude. Knowledge translation of educational interventions targeting registered nurses can often, but not always, improve patients' quality of life [36]. Therefore, knowledge, skills and attitudes regarding pain control after a PMP should be used and utilized to perform actions with a full under- standing of pain assessment and management to improve the quality of life among hospitalized patients. Knowledge must not only be acquired but also remembered, retained and utilized.

The limitations of the current study are acknowledged. Lack of staff and unit workload prevented them from participating in the current study. In addition, the sample was restrained to one governmental hospital in the United Arab Emirates, which may not be generalized to other health care sectors. Another limitation that was considered was the possibility of guessing when answering the true/false and multiple-choice questions, which could have affected the participants' score. Face-to-face interviews can be used to avoid such a risk.

\section{Conclusion and Recommendation}

In-service education PMP proved to be effective. Pain knowledge and attitudes were improved after the educational session. Nurses in the experimental group were scored higher in the post-test but still did not reach the passing score of $75 \%$. However, the knowledge scores increased significantly after implementing the PMP. As concluded from the current study, well-structured in-service education sessions are able to improve knowledge and show an impact on attitude changes. The authors will suggest including the PMP as an essential session of a general orientation program for newly hired staff. In addition, continuous staff evaluation and pain management competency should be taken into consideration. An ongoing need exists for more effective evidence-based education programs in pain management. Interactive teaching strategies, such as on-the-job training, improvisational learning, and case studies, should be tested for their influence on pain knowledge and attitudes and patient outcomes. 
Since the PMP proved to be effective, it is recommended to be implemented in the daily nursing practice. The authors of the current study conducted a previous study to address the knowledge and attitude in their hospital. Since the results have shown poor knowledge and attitude, an educational session was conducted by the in-service education department to improve the challenges. The third project of the authors will be to assess the impact of the pain education program on the patients' quality of life.

\section{Acknowledgment}

The authors would like to thank the participants who dedicated their time to enroll in our study.

\section{Statement of Ethics}

Ethical approval was obtained from the Dubai Scientific Research Ethics Committee in Dubai Health Authority (DHA) prior to data collection.

\section{Disclosure Statement}

The authors declare that they do not have conflicts of interest. All authors read and approved the submitted version. All authors confirm that the manuscript is their own original work.

\section{Funding Sources}

This study was not funded by any organization.

\section{Author Contributions}

N.A.S.: The principle investigator, corresponding author and data analyst.

R.J.: Lecturer, data collector and data entry.

N.A.: Co-author and proofreading.

F.C.: Manuscript revision, completing and follow-up of the ethical approval with the Scientific Research Dubai Committee.

A.J.: Lecturer, data collector and data entry.

\section{References}

1 Jain AA, Yeluri R, Munshi AK. Measurement and assessment of pain in children-a review. J Clin Pediatr Dent. 2012;37(2):125-36.

2 Twycross A. What is the impact of theoretical knowledge on children's nurses' post-operative pain management practices? An exploratory study. Nurse Educ Today. 2007 Oct; 27(7):697-707.

3 Kastrup M, von Dossow V, Seeling M, Ahlborn R, Tamarkin A, Conroy P, et al. Key performance indicators in intensive care medicine. A retrospective matched cohort study. J Int Med Res. 2009 Sep-Oct;37(5):1267-84.

4 Kehlet $\mathrm{H}$, Jensen T, et al. Persistent postsurgical pain: risk factors and prevention. Lancet. 2006 May 13;367(9522):1618-25.

5 Puntillo KA, White C, Morris AB, Perdue ST, Stanik-Hutt J, Thompson CL, et al. Patients' perceptions and responses to procedural pain: results from Thunder Project II. Am J Crit Care. 2001 Jul;10(4):238-51.

6 Al-Atiyyat N, Salim NA, Tuffaha MG, Abu Nigim HA, Saleh MM, et al. A Survey of the Knowledge and Attitudes of Oncology Nurses toward Pain in United Arab Emirates Oncology Settings. Pain Manag Nurs. 2019 Jun; 20(3):276-83.

7 Yildirim YK, Cicek F, Uyar M. Knowledge and attitudes of Turkish oncology nurses about cancer pain management. Pain Manag Nurs. 2008 Mar;9(1):17-25.

Effect of In-Service Education on Pain Management
8 Bernardi M, Catania G, Lambert A, Tridello G, Luzzani M. Knowledge and attitudes about cancer pain management: a national survey of Italian oncology nurses. Eur J Oncol Nurs. 2007 Jul;11(3):272-9.

9 Shahriary S, Shiryazdi SM, Shiryazdi SA, Arjomandi A, Haghighi F, Vakili FM, et al. Oncology Nurses Knowledge and Attitudes Regarding Cancer Pain Management. Asian Pac J Cancer Prev. 2015;16(17):7501-6.

10 Eid T, Manias E, Bucknall T, Almazrooa A. Nurses' knowledge and attitudes regarding pain in Saudi Arabia. Pain Manag Nurs. 2014 Dec;15(4):e25-36.

11 Brunier G, Carson MG, Harrison DE. What do nurses know and believe about patients with pain? Results of a hospital survey. J Pain Symptom Manage. 1995 Aug;10(6):436-45.

12 Brant JM, Keller L, McLeod K, Yeh C, Eaton LH. Chronic and Refractory Pain: A Systematic Review of Pharmacologic Management in Oncology. Clin J Oncol Nurs. 2017 Jun;21(3 Suppl):31-53.

13 Estabrooks CA, Knopp-Sihota JA, Norton PG. Practice sensitive quality indicators in RAI-MDS 2.0 nursing home data. BMC Res Notes. 2013 Nov; 6(1):460.

14 Fishman SM, Young HM, Lucas Arwood E, Chou R, Herr K, Murinson BB, et al. Core competencies for pain management: results of an interprofessional consensus summit. Pain Med. 2013 Jul;14(7):971-81.
15 Ware LJ, Bruckenthal P, Davis GC, O’ConnerVon SK. Factors that influence patient advocacy by pain management nurses: results of the American society for pain management nursing survey. Pain Manag Nurs. 2011 Mar; 12(1):25-32.

16 Hirsh AT, Jensen MP, Robinson ME. Evaluation of nurses' self-insight into their pain assessment and treatment decisions. J Pain. 2010 May;11(5):454-61.

17 Schafheutle EI, Cantrill JA, Noyce PR. Why is pain management suboptimal on surgical wards? J Adv Nurs. 2001 Mar;33(6):728-37.

18 Bennet DS, Carr DB. Opiophobia as a barrier to the treatment of pain. J Pain Palliat Care Pharmacother. 2002;16(1):105-9.

19 Wilson B. Nurses' knowledge of pain. J Clin Nurs. 2007 Jun;16(6):1012-20.

20 Altmann TK. Attitude: a concept analysis. Nurs Forum. 2008 Jul-Sep;43(3):144-50.

21 Jarrett A, Church T, Fancher-Gonzalez K, Shackelford J, Lofton A. Nurses' knowledge and attitudes about pain in hospitalized patients. Clin Nurse Spec. 2013 Mar-Apr;27(2): 81-7.

22 Dalton JA, Carlson J, Mann JD, Blau W, Bernard S, Youngblood R. An examination of nursing attitudes and pain management practices. Cancer Pract. 1998 Mar-Apr;6(2):11524. 
23 Qadire M, Khalaileh M. Effectiveness of educational intervention on Jordanian Nurses' knowledge and attitude regarding pain management. Br J Med Med Res. 2014;4(7):146072.

24 Ferrell BR, McCaffery M. Knowledge and At titudes Survey Regarding Pain. Available from: http://prc.coh.org/Knowldege $\% 20 \% 20$ $\& \% 20$ Attitude $\% 20$ Survey\%207-14\%20(1). pdf.

25 Allard P, Maunsell E, Labbé J, Dorval M. Educational interventions to improve cancer pain control: a systematic review. J Palliat Med. 2001;4(2):191-203.

26 Bennett MI, Bagnall AM, José Closs S. How effective are patient-based educational interventions in the management of cancer pain? Systematic review and meta-analysis. Pain. 2009 Jun;143(3):192-9.
27 Gugsa N, Sjetne I, Helles R. The Impact of an In-service Educational Program on Nurses' Knowledge and Attitudes Regarding Pain Management in an Ethiopian University Hospital. Front Public Health. 2018;6:229.

28 Zhang CH, Hsu L, Zou BR, Li JF, Wang HY, Huang J. Effects of a pain education program on nurses' pain knowledge, attitudes and pain assessment practices in China. J Pain Symptom Manage. 2008 Dec;36(6):616-27.

29 Ferrell BR, Grant M, Ritchey KJ, Ropchan R, Rivera LM. The pain resource nurse training program: a unique approach to pain management. J Pain Symptom Manage. 1993 Nov; 8(8):549-56.

30 Machira G, Kariuki H, Martindale L. Impact of an educational pain management programme on nurses pain knowledge and attitudes in Kenya. Int J Palliat Nurs. 2013 Jul; 19(7):341-6.

31 Gustafsson M, Borglin G. Can a theory-based educational intervention change nurses' knowledge and attitudes concerning cancer pain management? A quasi-experimental design. BMC Health Serv Res. 2013 Aug; 13(1): 328.
32 De Rond J, de Wit R, Van Dam M, van Campen B, et al. Daily pain assessment: value for nurses and patients. J Adv Nurs. 1999 Feb; 29(2):436-44

33 Sharif F, Ansari H, Mosalaee A, Jafaree P, Zinat $M$. The Effect of Pain Management Education on the Intensity of Pain and Quality of Life of Patients with Cancer. J Palliat Care Med. 2012;2(4):114.

34 Tse MM, Ho SS. Enhancing knowledge and attitudes in pain management: a pain management education program for nursing home staff. Pain Manag Nurs. 2014 Mar; 15(1):2-11.

35 Cummings GG, Olivo SA, Biondo PD, Stiles CR, Yurtseven O, Fainsinger RL, et al. Effectiveness of knowledge translation interventions to improve cancer pain management. J Pain Symptom Manage. 2011 May;41(5): 915-39. 